\section{Synthesis of}

Heterocycles

\section{Key words}

indoles

azaindoles

Heck coupling

Buchwald-Hartwig cross-coupling

palladium catalysis

\title{
Palladium-Catalyzed C-N/C-C Coupling Route to Substituted Indoles
}

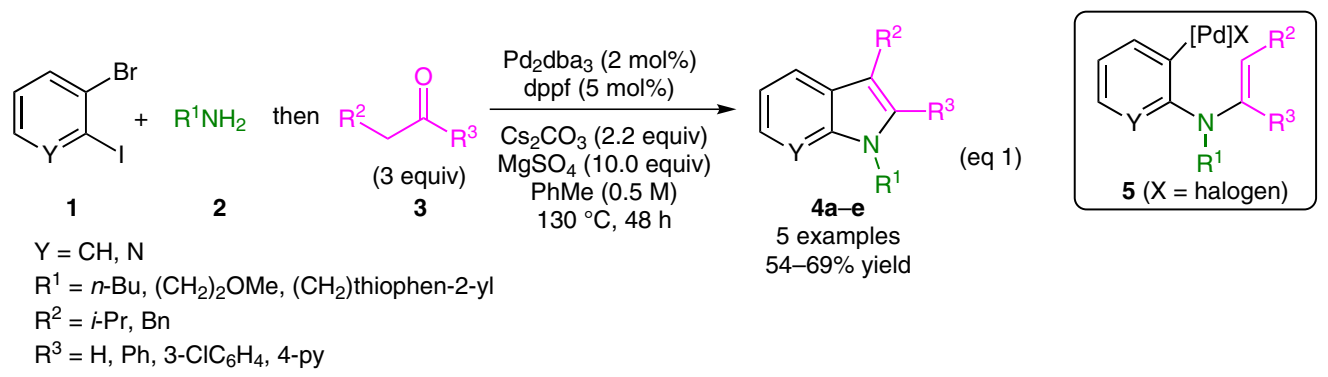

Other examples:

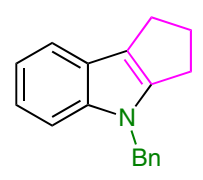

$\mathbf{4 f}(68 \%$ yield $)$

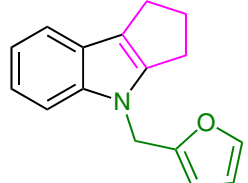

$\mathbf{4 g}(63 \%$ yield $)$<smiles>COc1ccc2c3c(n(Br)c2c1)CCCC3</smiles>

4h $(52 \%$ yield $)$

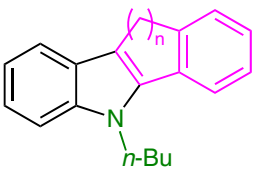

$4 i \mathrm{n}=1(59 \%$ yield $)$ $4 j \mathrm{n}=2(52 \%$ yield $)$
Significance: Reported is the one-pot synthesis of highly substituted indoles 4 via a sequential palladium-catalyzed $\mathrm{C}-\mathrm{N}$ and $\mathrm{C}-\mathrm{C}$ coupling reaction of 0 -bromoiodo arenes $\mathbf{1}$, carbonyl derivatives $\mathbf{3}$, and amines 2 . The reaction is proposed to proceed by $\mathrm{C}-\mathrm{N}$ coupling to generate aryleneamine intermediate $\mathbf{5}$ which undergoes an intramolecular arene-alkene coupling reaction (eq 1). This sequence of events is supported by an adequate number of experiments. The authors also suggest that the mechanism of the final step differs from a traditional Heck reaction. Among several ligands, bases and solvents tested, 1,1'-bis(diphenylphosphanyl)ferrocene (dppf) in combination with a weak base $\left(\mathrm{Cs}_{2} \mathrm{CO}_{3}\right)$ in toluene was suited best. The addition of $\mathrm{MgSO}_{4}$ proved beneficial, presumably by favoring eneamine formation. The reaction failed when $\mathrm{Pd}(\mathrm{OAc})_{2}$ was used in place of $\mathrm{Pd}_{2} \mathrm{dba}_{3}$. Both aldehydes and cyclic/acyclic ketones gave moderate yields of indoles. Two examples of azaindoles $(Y=N)$ were also reported. $A$ pyridine derivative $\left(R^{3}=4-p y\right)$ was also tolerated.
Comment: The synthesis and functionalization of indoles has been a major area of focus for organic chemists due to its importance in the pharmaceutical field (see Book below). Numerous synthetic methods for indoles including Fischer indole synthesis and its modifications have been reported (see Review below). The current one-pot threestep method provides highly functionalized indoles in moderate yield using readily available starting materials. Although it was indicated that the reaction failed with a carbomethoxy derivative of $\mathbf{3}$, the reaction scope and limitations were not well investigated.

Book: Heterocyclic Scaffolds II: Reactions and Applications of Indoles, Vol. 26.; G. W. Gribble, Volume Ed.; In Topics in Heterocyclic Chemistry; B. U. W. Maes, Series Ed.; Springer: New York, 2010.

Review: G. R. Humphrey, J. T. Kuethe Chem. Rev. 2006, 106, 2875-2911. 